\title{
PROSES KREATIF LAMBANG INSTITUT SENI INDONESIA YOGYAKARTA
}

\author{
Subroto Sm. \\ Dosen Program Studi Seni Rupa Murni \\ Jurusan Seni Murni FSR ISI Yogyakarta \\ Email: subrotosm@yahoo.com
}

\section{Pengantar}

Puji syukur ke hadirat Tuhan Yang Mahabaik dan Mahaindah, yang atas izin-Nya kita semua dikaruniai kesempatan untuk memajukan dan mengembangkan ISI Yogyakarta. Sebagai pengantar perlu diketahui bahwa, profesi utama saya pelukis dan mantan guru yang menggemari fotografi, keramik, sedikit musik dan desain grafis. Jadi, saya bukan ahlinya desain grafis atau tukang lambang. Saya hanya salah seorang yang kebetulan ketiban sampur untuk mencipta lambang ISI Yogyakarta.

Berbekal dari keterlibatan saya bersama Pak Parsuki dalam proses lahirnya lambang ISI Yogyakarta saya ingin menyumbangkan sekelumit kisah yang diharapkan bermanfaat bagi perjalanan ISI Yogyakarta, Fakulas Seni Rupa khususnya.

\section{Mengapa Dewi Saraswati?}

Sehari setelah peresmian/pelantikan Rektor pertama ISI Yogyakarta, pada malam hari tanggal 24 Juli 1984, di Sasana Ajiyasa diadakan pertemuan Rektor dengan pimpinan STSRI ASRI/FSRD; saya sebagai Ketua Jurusan Seni Lukis dan Drs. Parsuki sebagai Ketua Jurusan Disain Komunikasi, termasuk diundang. Pertemuan ini selain sebagai perkenalan/silahturahmi antara "warga STSRI ASRI" dengan rektor baru, bertujuan untuk menyusun langkah-langkah baru yang diperlukan bagi ISI Yogyakarta. Di akhir acara Pak Parsuki dan saya diberitahu Pak Saptoto, Dekan FSRD untuk membentuk panitia Sayembara Lambang ISI Yogyakarta, karena lambang ini sangat diperlukan (ISI pada awal berdirinya secara yuridis memiliki tiga Fakultas dengan sebutan: (1) Fakultas Kesenian (dh. ASTI dan AMI); (2) Fakultas Seni Rupa dan Disain (dh. STSRI “ASRI"); dan (3) Fakultas Nongelar Kesenian).

Pada keesokan harinya, Rabu 25 Juli, Pak Saptoto memberikan Memo Dinas untuk melaksanakan sayembara itu kepada Pak Parsuki dan saya. Dari lima butir memo itu yang paling memo pada butir tiga dan empat, yaitu: "III. Titikberat daripada peserta sayembara tsb. di utamakan bagi kalangan Dosen Muda dan Mhs. IV. Batas waktu sayembara di harapkan final sudah dapat dikumpulkan hari Selasa 31 Juli '84." Sejalan dengan memo dinas tsb. terbentuklah Panitia Sayembara. Pak Parsuki sebagai ketua, saya sebagai sekretaris, dilengkapi dengan Dewan Juri merangkap sebagai anggota terdiri dari: Drs. Parsuki (ketua) dan anggota2nya: Drs. Aming Prayitno, Drs. Sudarisman (FSRD); T. Adimurti, Dip.M dan Y. Sumandiyo Hadi, SST(Fakultas Kesenian).

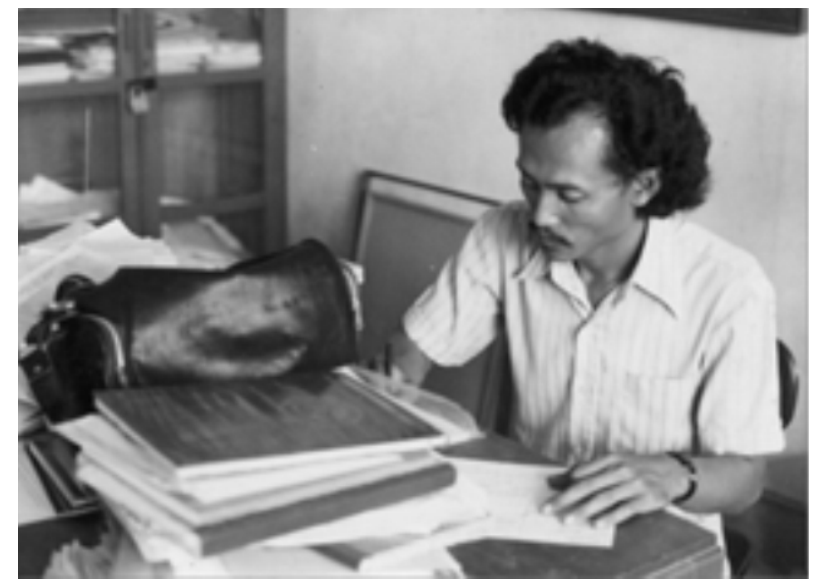

Gambar 1. Drs. Subroto Sm. di meja kerja saat menjabat Ketua Jurusan Seni Lukis (1984) (dok: Subroto, Sm.) 
Sampai dengan 31 Juli, menurut penilaian Dewan Juri terhadap 29 desain dari 27 orang peserta yang masuk, dinyatakan tidak ada desain yang dianggap memenuhi syarat. Selanjutnya, dekan menginstruksikan agar diadakan sayembara susulan dan harus selesai 4 Agustus. Pada tahap susulan, dewan juri menilai 12 desain dari 12 peserta yang masuk, juga tidak ada desain yang diterima/memenuhi syarat. Berdasarkan hasil sayembara ini Dewan Juri mengusulkan dibentuk Tim Khusus Pencipta lambang ISI yang terdiri dari Drs. Parsuki, Drs. Aming Prayitno, Drs. Subroto Sm, dan Drs. Sudarisman.

Pada tanggal 6 Agustus, Tim Khusus melaporkan hasil sayembara kepada Rektor, didampingi Dekan FSRD dan Bapak Widayat. Hasil pertemuan dengan Rektor menghasilkan keputusan: (1) menetapkan desain karya Sdr. Lasiman, Setyo Budiman, dan Bagus Jatmiko terpilih sebagai tiga karya masuk nominasi. (2) Tim Khusus diminta segera menciptakan lambang ISI, mengingat lambang tsb. akan digunakan untuk kepentingan administrasi dan publikasi.

Sebetulnya aneh juga lembaga berdiri belum menyiapkan lambang. Namun hal demikian sering kita jumpai pada beberapa organisasi atau lembaga baru. Yang pasti, walaupun Rektor tidak menyebut tanggal dan bulan, lambang ISI harus segera diciptakan.

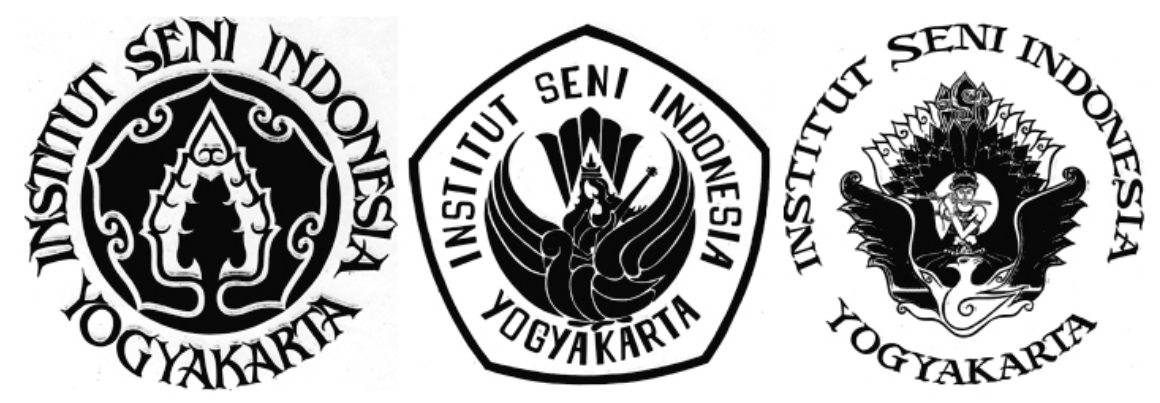

Gambar 2. Tiga nominator pemenang desain lambang ISI Yogyakarta karya mahasiswa JurusanDisain Komunikasi FSRD ISI Yogyakarta: Sdr. Lasiman, Setyo Budiman, dan Bagus Jatmiko (dok: Subroto, Sm.)
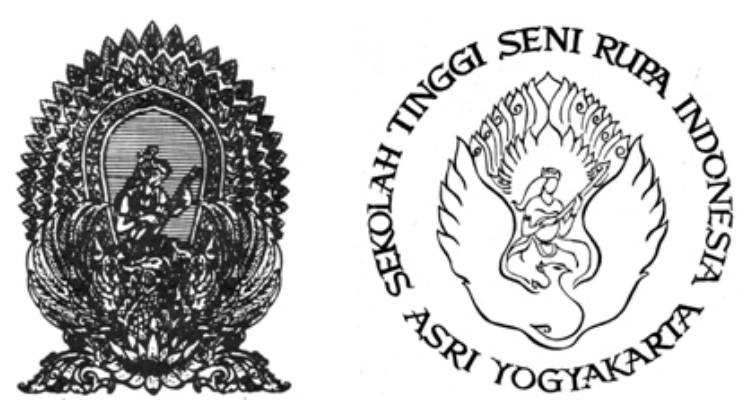

Gambar 3. Lambang ASRI dan Lambang STSRI ASRI (dok: Baskoro SB)
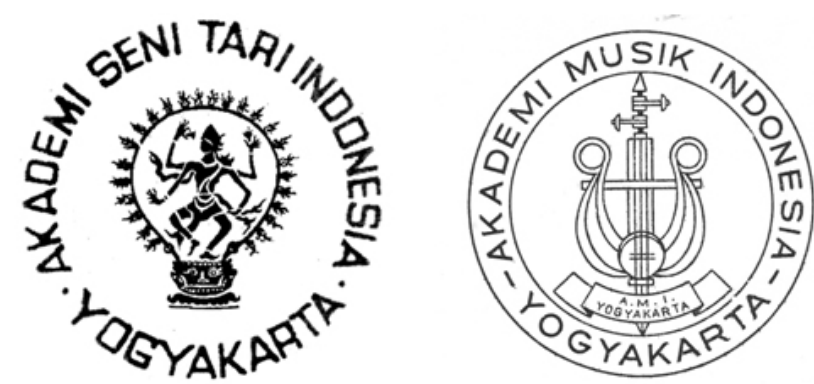

Gambar 4. Lambang ASTI dan Lambang AMI (dok: Baskoro SB) 
Akhirnya, dalam sayembara yang kedua ditambahkan persyaratan: makna kesatuan unsur-unsur seni supaya dilukiskan dengan Dewi Saraswati dalam bentuk baru. Hal ini ditetapkan berdasarkan acuan Ensiklopedia Indonesia bahwa Saraswati adalah dewi kesenian dan ilmu pengetahuan dalam agama Hindu di India dan Bali. Sehingga, Dewi Saraswati menjadi pilihan paling tepat dan luwes untuk dijadilan unsur bentuk utama penciptaan lambang ISI sebagi lembaga pendidikan tinggi di mana ilmu dan seni diajarkan.

\section{Dewi Saraswati:}

\section{dari yang Ornamentik ke yang Linier Konstruktif}

Dewi Saraswati dalam bentuk baru telah menjadi pilihan/syarat utama untuk lambang ISI. Pertanyaannya, bagaimana melukiskan dewi saraswati dalam bentuk baru, untuk lambang yang dapat menggambarkan tujuan ISI Yogyakarta sebagai institut pendidikan tinggi seni yang pertama dan terkemuka di Indonesia? Soal inilah yang ternyata tidak mudah dipecahkan oleh peserta sayembara dan juga kemudian oleh Tim Khusus yang saya ikut terlibat di dalamnya.

Perlu disampaikan di sini, tanpa mengurangi rasa hormat saya kepada anggota tim yang lain, Pak Aming dan Pak Darisman, bahwa proses pembuatan lambang ISI, mulai 6-23 Agustus 1984, dalam kenyataannya saya dan Pak Parsuki yang banyak mengadakan komunikasi intensif, baik di antara kami berdua atau dengan Pak But. Sehingga kami berdua produktif membuat berbagai desain alternatif. Sebagai catatan, Pak Aming membuat dua lembar desain, dan Pak Darisman menyerahkan tugasnya kepada tiga anggota tim lainnya. Jika dianalisis, berbagai alasannya antara lain: (1) manajemen tim kurang bagus, (2) saya dan Pak Parsuki orang pertama yang menerima "beban mulia" mendapat "memo Dinas" dari pimpinan; (3) kami masing-masing sebagai ketua jurusan sering ketemu dalam forum-forum rapat dengan pimpinan; dan (4) secara jujur saya mengakui seperti kecanduan mendesain pada waktu itu.

\section{Konsep Desain 1: mengarah pada gaya Klasik Ornamentik}

Sejak tugas sebagai tim khusus diberikan, konsep bentuk lambang yang saya jadikan pegangan adalah: (1) Membumi, (2) Esensial dan unik (3) Tidak berbentuk segilima. Terus terang pada awalnya sulit menghilangkan ingatan akan bentuk lambang ASRI dan STSRI ASRI, yang kebetulan kedua lambang itu sudah menggunakan Dewi Saraswati sebagai bentuk utama. Maka, dalam banyak desain yang saya buat masih terbawa ke lambang ASRI. Bedanya, kini Saraswati bertangan empat dan naik angsa, karena angsa sebagai kendaraan Saraswati dianggap lebih bermakna dibandingkan burung merak.

Konsep membumi saya terapkan dengan mengacu pada motif-motif batik atau wayang kulit. Namun, dalam pelaksanaannya saya terjebak pada bentuk-bentuk ornamentik dan masih terkesan kuat mirip lambang ASRI, masih ada bentuk segi-limanya, dan bahkan bentuknya tidak esensial dan kurang unik sebagaimana yang saya inginkan.
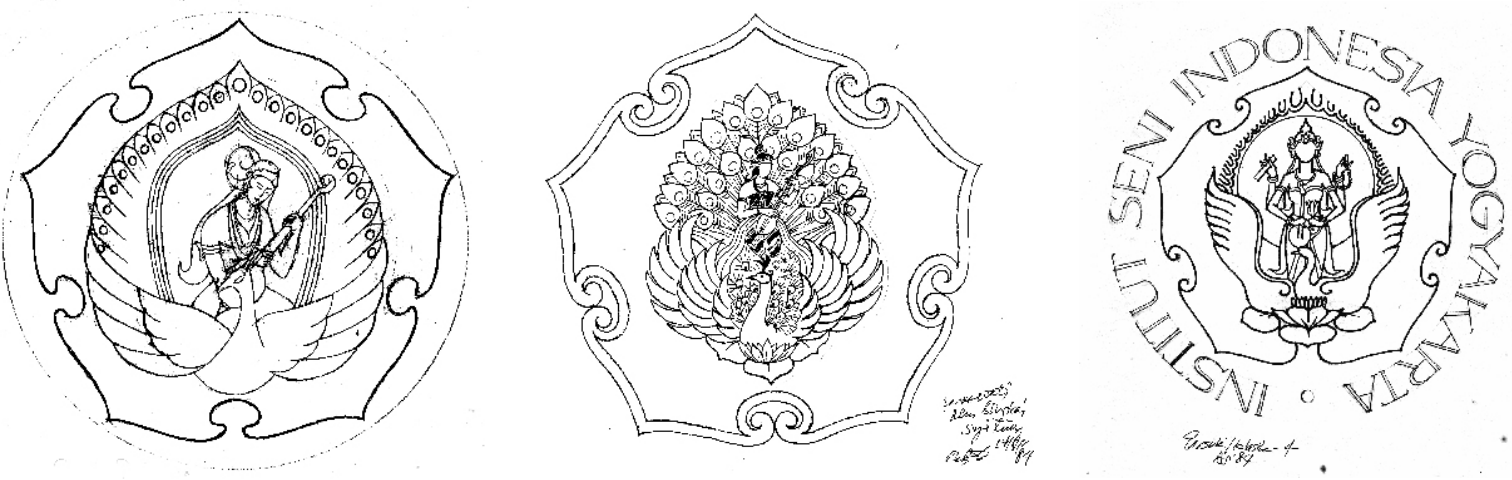

Gambar 5. Tiga rancangan awal lambang ISI Yogyakarta, bergaya klasik karya Drs. Aming Prayitno, Drs. Subroto Sm dan Drs. Parsuki. (dok: Subroto, Sm.) 
Ketika waktu terasa semakin cepat berjalan, pada tanggal 10 Agustus 1984, saya dan Pak Parsuki diundang Rektor untuk menunjukkan beberapa desain yang sudah dibuat. Dari hasil pertemuan itu, menurut beliau belum ada desain terpilih. Kemudian beliau memberi contoh dengan menggambar sebuah desain lambang ISI berbasis bentuk lingkaran dengan pensil pada kertas folio bergaris. Digambarkan dewi saraswati naik angsa, keempat tangan dalam struktur menutup, di belakang ada tiga kelopak bunga teratai yang ujung-ujungnya meruncing berbasis bentuk lingkaran, mirip bentuk bawang. Sambil menggambar, Pak But menyarakan kepada kami berdua untuk mengembangkan desain lambang yang berbasis lingkaran dan konstruktif. Tujuannya, agar lambang terkesan momumental dan mudah pengerjannya untuk berbagai aplikasinya.

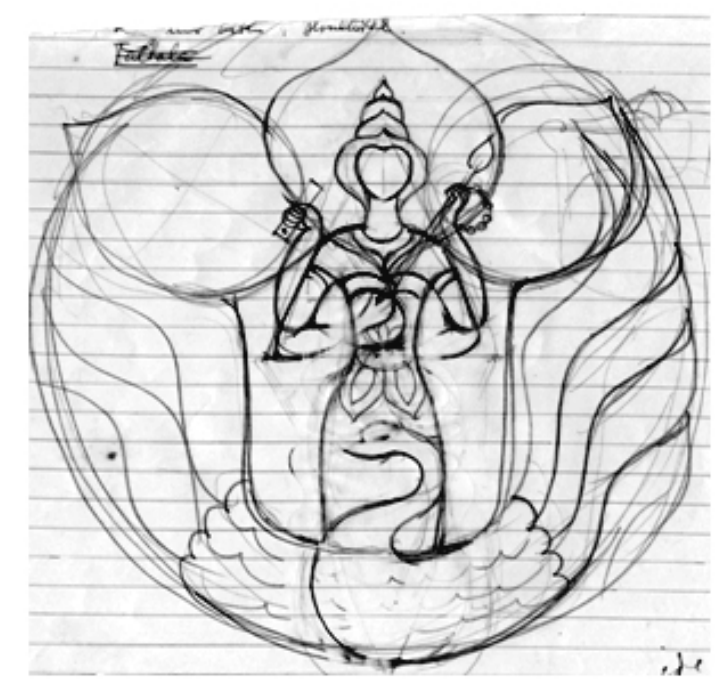

Gambar 6. Lambang ISI Yogyakarta sebagai masukan kepada Tim perancang hasil goresan Pak But Muchtar. (dok: Subroto, Sm.)

\section{Konsep Desain 2: Simpel, Simetris, dan Konstruktif}

Berdasarkan prinsip desain dan contoh yang diciptakan Pak But, saya dan Pak Parsuki mengembangkan desain-desain baru yang simpel, simetris dan konstruktif. Kami berdua semakin produktif mendesain. Semua desain alternatif yang kami ciptakan memiliki kerangka bentuk lingkaran dan segi-empat. Adapun unsur-unsur lambang yang harus digambarkan adalah: Pancasila, Tridharma PT, Saraswati bertangan empat dengan benda-benda bawaannya, angsa, dan bunga teratai.

Dalam pengalaman saya, kadang melelahkan/menjemukan ketika saya harus memasukkan atau menggabungkan bentuk-bentuk yang memiliki makna-makna tertentu. Namun, di saat yang lain ketika masing-masing motif atau bagian bentuk, yang "sarat pesan/makna" itu dapat saling berintegrasi secara harmonis, rasanya saya didorong terus untuk menemukan bentuk yang lebih indah, karena rasanya selalu ada yang kurang. Tujuan akhir yang saya inginkan adalah kesatuan bentuk dan isinya yang simpel dan unik.

Tiga contoh dapat saya kemukakan, yang pada waktu itu membuat saya keasyikan atau penasaran mendesain. Pertama, misalnya ketika mengembangkan bentuk tangan-tangan Saraswati; mana yang lebih indah dan bermakna, yang arah membuka atau menutup? Kedua, bagaimana agar karakter membumi yang terinspirasi dari motif Grudha (garuda) itu terkesan inovatif tidak semata-mata mirip Garuda Pancasila atau motif batik yang asli? Ketiga, bagaimana melalui garis dapat digambarkan berbagai bentuk bermakna itu agar terasa mengalir dan menyatu secara utuh, dinamis, dan luwes. 


\section{Kerja Kreatif, Ada Batasnya}

Kapan kita harus memutuskan desain kita selesai? Sebagaimana dinyatakan George Santayana, bahwa proses kreatif adalah kegiatan yang sadar tujuan. Jadi, jika tujuan desain dianggap tercapai, kerja mendesain selesai. Itulah kira-kira pedomannya. Namun, dalam pelaksanaannya tidak semudah itu. Demikian pula yang saya dan Pak Parsuki alami.

Pada tanggal 25 Agustus 1984, kami berdua menemui Rektor untuk menunjukkan beberapa desain. Yang menarik dalam pertemuan itu adalah, karena saya sering cerewet, seingat saya Pak But lebih kurang menyatakan: "Sudahlah Tok, kerja mendesain ada batasnya. Kalau mau dicari terus, pasti ada kekurangannya."

Akhirnya, Pak But memilih dan menetapkan sebuah desain yang kini menjadi lambang ISI Yogyakarta, dengan membubuhkan tulisan "Disetujui untuk dipergunakan sebagai lambang ISI Yogyakarta" tertanggal 25 Agustus 1984 dan tandatangan menggunakan tinta berwarna biru pada fotocopy desain lambang ISI Yogyakarta. Beliau meminta kami berdua segera menyiapkan stempel, kop surat, rumusan lambang, dan gambar konstruksinya.

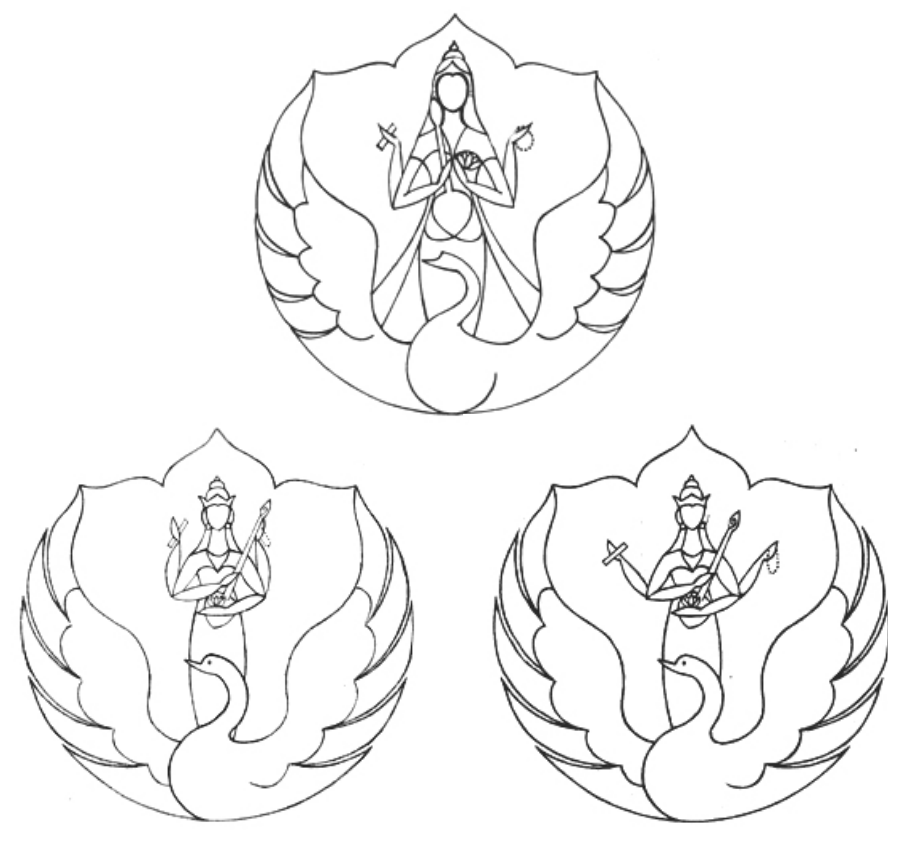

Gambar 7. Rancangan awal lambang ISI Yogyakarta setelah mendapat masukan dari Pak But. Atas karya Drs. Parsuki, kiri dan kanan bawah karya Drs. Subroto Sm.(dok: Subroto, Sm.)
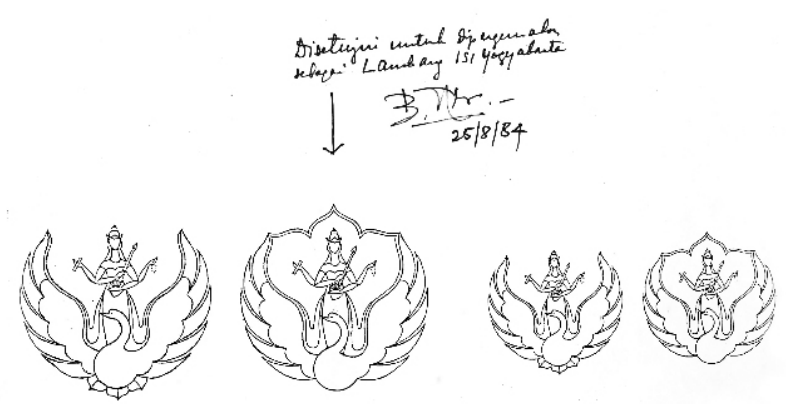

Gambar 8. Rancangan lambang ISI Yogyakarta yang telah disetujui dan mendapat acc Rektor ISI Yogyakarta, Drs. But Muchtar. (dok: Subroto, Sm.) 


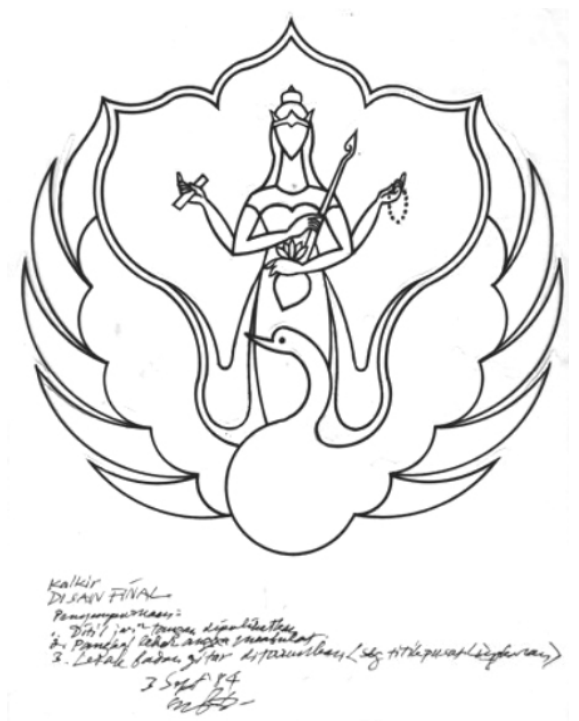

Gambar 9. Lambang ISI Yogyakarta terpilih karya Drs. Subroto, Sm. dan Drs. Parsuki. (dok: Subroto, Sm.)

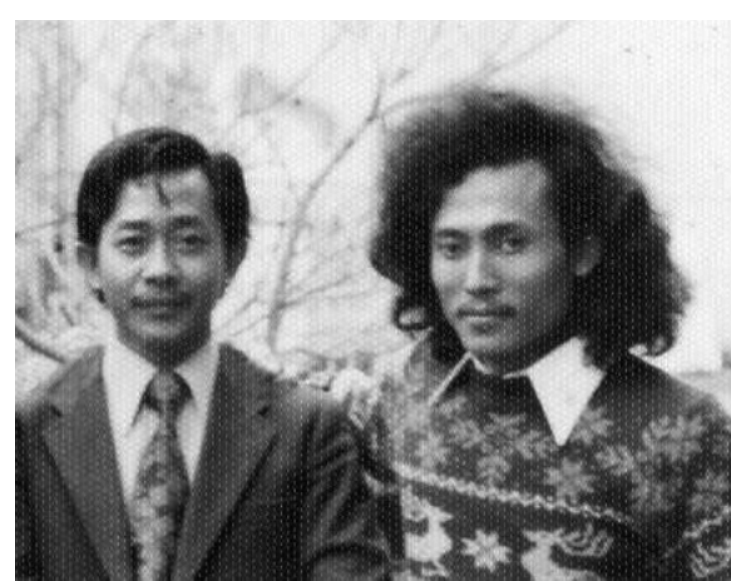

Gambar 10. Parsuki dan Subroto, Sm, Osaka Jepang foto diambil tanggal 13 Maret 1976. (dok: Subroto, Sm)

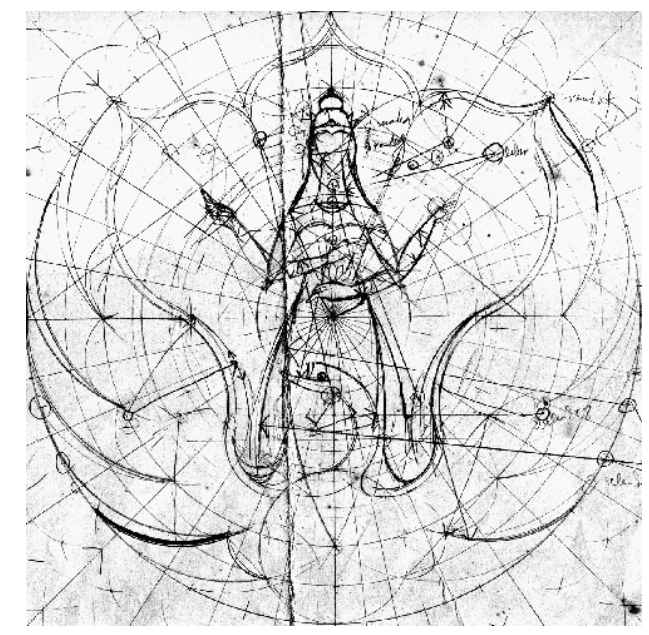

Gambar 11. Gambar teknik lambang terpilih (dok: Subroto, Sm.) 


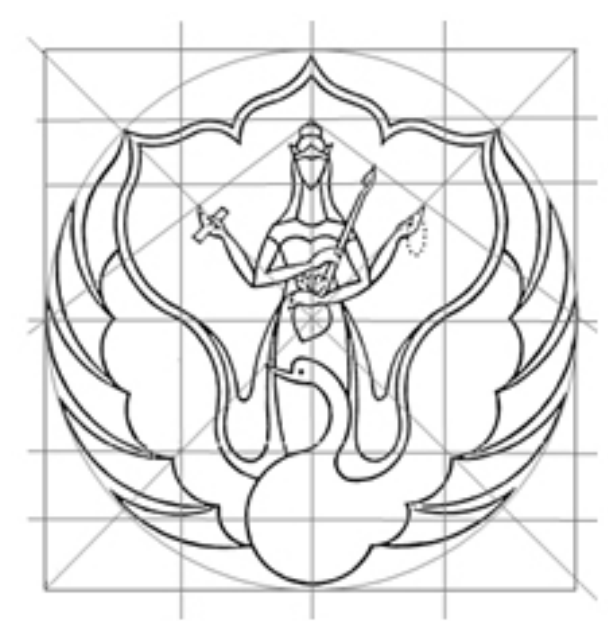

Gambar 12. Grid Standard Manual (GSM), lambang ISI Yogyakarta (dok: Subroto, Sm.)

\section{Tinjauan Kritis dan Harapan}

Sejak lambang ISI Yogyakarta ditetapkan, selanjutnya dibuat berbagai bentuk aplikasi/reproduksinya untuk keperluan publikasi dan administrasi. Pada akhir kerja panitia, saya menyerahkan berkas-berkas/dokumen tentang desain lambang ISI Yogyakarta kepada Purek II, Bapak Soedarso Sp., MA. Dalam Buku Petunjuk Akademik ISI Yogyakarta 1985, telah dicantumkan Lambang ISI Yogyakarta beserta penjelasan arti lambang hasil penyempurnaan Pak Darso. Sebelum itu, dalam merumuskan isi makna lambang, panitia mengacu pada beberapa sumber pustaka dan masukan dari Bapak KKS Kadi, BA, mantan Sekretaris Direktur STSRI ASRI yang juga sebagai Ketua Parisada Hindu Dharma DIY.

Terdapat temuan-temuan lucu dan menarik, ketika lambang ISI Yogyakarta diaplikasikan. Menurut hemat saya lambang ISI Yk ini tampaknya simpel, tetapi boleh juga dibilang rumit. Apalagi jika dikerjakan secara manual. Namun, di era digital ini pun, masih dijumpai penggambaran lambang ISI yang kadang-kadang menyimpang. Hal demikian adalah wajar dan manusiawi. Sepanjang yang memesan dan yang mereproduksi lambang tidak mengerti aturan bakunya, kesalahan-kesalahan kecil hingga besar pasti muncul. Bagi yang memahami dan menyadari fungsi lambang, apalagi pemiliknya, hendaklah kesalahan-kesalahan itu dihindari atau dieliminasi. Namun dalam kenyataannya, tidak jarang aplikasi lambang itu produk resmi dari dan untuk ISI Yogyakarta sendiri terdapat kesalahan yang beragam. Lihat beberapa contoh berikut: kesalahan "kecil" yang sering dijumpai adalah letak/arah lambang terbalik. Angsa yang seharusnya menghadap ke kanan, tetapi menghadap ke kiri. Kejanggalan berikut adalah, bentuk lambang didistorsi secara manual maupun digital, angsanya kurus (condensed) atau terlalu tambun (expanded). Kesalahan fatal terjadi ketika pemesan dan pembuat reproduksi lambang bertindak ceroboh, yaitu lambang ISI Yogyakarta dibuat seenaknya sendiri.

Diketahui, memang lambang ISI Yogyakarta sejauh ini belum memiliki standar aturan dan pedoman pemanfaatan/aplikasinya secara lengkap. Oleh karenanya perlu disempurnakan oleh sebuah tim ahli yang melibatkan Prodi Disain Komunikasi Visual FSR. Menurut hemat saya, jika lembaga menghendaki, melalui forum senat guru besar, lambang ISI Yogyakarta masih bisa diperbaharui, sepanjang tidak mengurangi filosofi, identitas atau karakter dasarnya.

Akhirnya, mohon maaf atas lebih-kurangnya semua hal yang saya sampaikan ini; dan saya siap diluruskan oleh pelaku sejarah lainnya. Sebagai catatan, sebelum saya menyusun naskah ini telah mengonfirmasi beberapa hal penting terkait proses desain dengan Pak Parsuki, Pak Aming Prayitno, dan Pak Sudarisman. Semoga dipicu dari tulisan saya ini, kesadaran dan kepekaan kita, sivitas akademika ISI Yogyakarta, tidak surut tetapi, kian tajam dalam menata dan meraih ISI Yogyakarta sebagai center of excellence pendidikan tinggi seni di Indonesia, khususnya melalui upaya penerbitan buku Sejarah Fakultas Seni Rupa atau secara khusus buku Sejarah Lambang ISI Yogyakarta. Semoga! 


\title{
RESENSI BUKU \\ "Designer Handbook Dalam Produksi Cetak \\ Dan Digital Printing"
}

\author{
Baskoro Suryo Banindro \\ Dosen Program Studi Disain Komunikasi Visual \\ Jurusan Disain FSR ISI Yogyakarta \\ Email: banindro@yahoo.com
}

\begin{abstract}
Penulis: Anne Dameria
Penerbit: Link \& Match Graphic

Tahun: 2012
\end{abstract}

ISBN: 978-979-97981-8-3

Tebal Buku: $180 \mathrm{Hal}$

Cetak: Full Color

Email:Info@link-match.com

Harga: Rp. 250.000,00

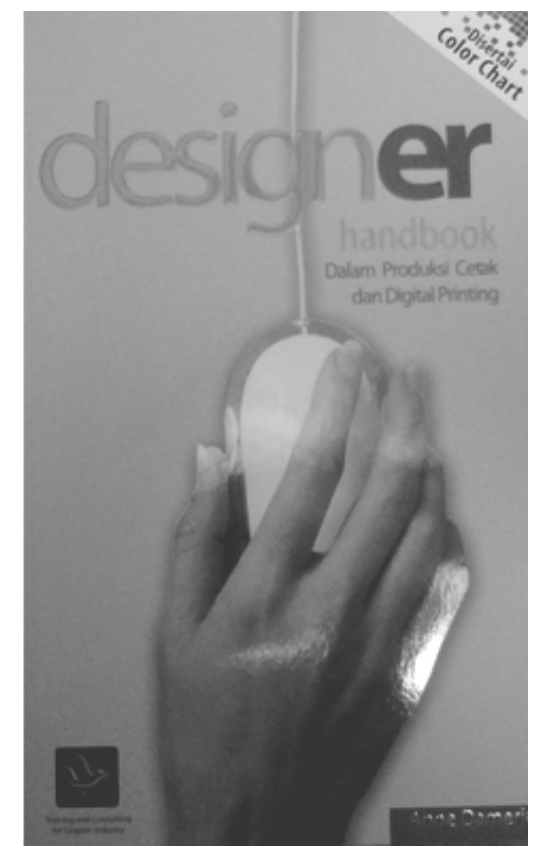

Sudah banyak buku yang membahas tentang metode reproduksi grafika, akan tetapi jarang yang menyertakan informasi tentang bagaimana menyiapkan standard file design. Anne Dameria seorang penulis buku metode reproduksi grafika, melalui pengalaman selain sebagai pengajar pada pendidikan dan pelatihan grafika, sekaligus praktisi dan konsultan grafika telah menyiapkan sebuah buku tentang pengenalan produk cetak dan printing digital bagi desainer. Buku ini terbagi menjadi 7 (tujuh) bab pembahasan ditambah satu paket color chart. Pada bagian pertama dibahas tentang arti pentingnya perencanaan yang matang untuk memulai sebuah produk cetakkan. Tujuan merancang dan siapa target audien, bagaimana pembaca akan menggunakan produk tersebut, bagaimana proses cetaknya, berapa oplah termasuk cost dan quality dijelaskan pada bagian ini.

Pada bagian kedua buku ini, dijelaskan tentang Standard File Design, yaitu mempersiapkan data digital. Kita diajak untuk mengikuti standar yang umum dilakukan dalam proses produksi cetak, pertama 
software yang digunakan disarankan menggunakan Photoshop, dikatakan oleh Anne Dameria bahwa software ini telah disiapkan sebagai software digital imaging yang khusus mengolah dan mendukung semua fasilitas yang diperlukan dalam mengolah gambar digital. Selanjutnya pemahaman tentang pentingnya format gambar asli, perlunya mengkonversi file RGB ke CMYK serta hal lain yang perlu diperhatikan, misalnya dalam penggunaan warna standard. Resolusi image, format file apakah TIFF, EPS, JPEG, PSD. Penyusunan vektor atau garis, ketebalan dan warna garis, font, ukuran file, warna dan ink coverage serta penyimpanan data digital merupakan bahasan yang disampaikan pada awal buku ini.

Pada bagian ketiga buku ini, dibahas tentang PDF file dengan tutorialnya untuk PDF dari Indesign, PDF dari illustrator, PDF dari Freehand MAX, dan PDF dari Freehand MX serta pentingnya memilih resolusi. Sementara bagian keempat menguraikan tentang proses print production, antara lain dijelaskan mengenai alur kerja percetakan, reproduksi warna pada cetak offset, pengertian raster, sudut raster, continuous tone dan half tone, serta screen ruling. Tahap berikutnya ialah membahas tentang Pre Press atau Pra Cetak, pada bagian ini diuraikan tentang proses cetak dari Computer to Film (CF) dan proses Computer to Plat (CtP) masing-masing dengan penjelasan kekurangan serta kelebihan, serta beberapa kiat tentang tips bagaimana menilai film separasi yang baik.

Press/cetak juga menjadi bagian pembahasan isi buku ini. Dijelaskan oleh Anne bahwa tahap cetak merupakan proses yang penting dalam produksi cetak. Parameter kualitas proses produksi dilandaskan pada pedoman presisi atau register, warna, kebersihan dan lainnya. Standarisasi cetak, Proses Standart Offset (PSO) yang menyangkut masalah ISO juga tak luput dari uraian pembahasan isi buku ini..

Bagian akhir dari bagian empat buku ini membahas tentang Post Pres atau tahap finishing. Dalam bahasan ini disebutkan bahwa tugas bagian finishing menanghani masalah bagaimana memotong kertas, melipat, mengkompliti, menjahit, mengelem dan lain-lain sesuai dengan jenis produknya masing-masing. Secara ditail diuraikan tentang jenis jilid yang ada dalam proses finishing ini dan tidak kurang dari 8 (delapan) jenis jilid dipaparkan dengan jelas menggunakan info grafis yang menarik. Berbagai jenis lipatan dan efek finishing melengkapi pembahasan bagian ini.

Bagian kelima dari isi buku Anne ini membahas tentang "Magic of Color", yaitu bagian awal membahas tentang Komunikasi Warna, kemudian Prinsip Dasar Warna dan pada bagian akhir membahas tentang Konsep Color Management. Pada bagian awal diuraikan tentang alur kerja dalam industri grafika, model warna yang membahas tentang hue, saturation, lightness, gamut warna dan warna spot. Dalam bahasan konsep Color Management dibahas mengapa terjadi perbedaan warna antara peralatan yang satu dengan lainnya dan bagaimana solusinya.

Bagian keenam membahas tentang Digital Printing, yang menguraikan tentang persiapan Desain dan Prepress, kemudian Digital Printing dan penggolongannya serta definisi tentang Digital Printing. Bahasan dalam bab ini menguraikan tentang pentingnya kreativitas dan kemampuan menguasai teknologi printing, apabila itu dilakukan maka yang muncul adalah sebuah disain yang dahsyat. Ragam aplikasi dalam "New Technology Digital Printing" divisualkan dengan beberapa contoh printing yang menarik. Bab ini juga menjelaskan tentang kelebihan digital printing terkait dengan kebutuhan Print On Demand (POD), kebutuhan Digital Color Proofing (DCP), kebutuhan Poster Dalam, kebutuhan Poster Luar. Lebih lanjut Anne dalam bab ini menjelaskan bagaimana memulai pekerjaan dengan tool yang benar antara lain, aplikasi untuk industri grafika, format file, teks dan fonts.

Bagian ketujuh isi buku ini mengapresiasi akan alternatif teknik cetak. Isinya antara lain menguraikan tentang teknologi cetak dengan acuan cetak permanen, teknologi cetak tanpa acuan cetak permanen. Uraian proses kerja cetak datar, cetak tinggi, cetak dalam dan cetak saring masing-masing mendapatkan penjelasan yang berimbang antara kelebihan dan kekurangan masing-masing teknik cetak yang ada. Bagian akhir dari bab ketujuh ini, dilengkapi dengan cara menggunakan color chart, tidak kurang dari 74 (tujuh puluh empat) halaman full color pedoman warna dan prosentase kebutuhan CMYK yang dibutuhkan. 
Melalui buku ini tidak saja kita dikenalkan akan pemahaman produksi cetak dan digital printing, akan tetapi bagaimana pra cetak, produksi cetak dan pasca cetak perlu mendapat perhatian bagi para desainer. Hari Wardjono selaku Direktur cetak Gramedia dalam kata pengantar buku ini mengatakan bahwa: ...banyak hal yang biasanya diajarkan secara lisan dari seorang disainer kepada disainer lainnya dan dijabarkan dengan jelas disertai ilustrasi, akan tetapi dengan membaca pengetahuan buku ini akan menghindarkan desainer dari permasalahan yang tidak perlu, karena disitulah letak kunci keberhasilan sebuah produksi cetak...

Sebagai kata penutup, buku ini kiranya dapat menjadi pedoman baik bagi para pemula maupun profesional produksi grafika yang sudah "berjalan", untuk mengaktualisasi hadirnya "paradigma baru" dalam hal ini teknologi digital printing sehingga lebih dapat meningkatkan kualitas dan ragam cetakkan sesuai selera jaman. 